\title{
PENGARUH PERCEIVED ORGANIZATIONAL SUPPORT, SELF EFFICACY, DAN LINGKUNGAN KERJA TERHADAP EMPLOYEE ENGAGEMENT KARYAWAN PT. PESONA ARNOS BETON
}

\author{
David Yusuf Firnanda \\ Universitas Negeri Surabaya \\ david.17080574014@mhs.unesa.ac.id \\ Dewie Tri Wijayati \\ Universitas Negeri Surabaya \\ dewiewijayati@unesa.ac.id
}

Abstract

\begin{abstract}
PT. Pesona Arnos Beton is one of the organizations engaged in concrete processing, which was founded in 2016. This research aims to examine the perceived organizational support, self-efficacy, and work environment on employee engagement of employees of PT. Pesona Arnos Beton. This study is a causality study with a quantitative approach. The sampling method used was a saturated sampling method with 80 respondents. The statistical analytical used in this study was Multiple Linear Regression analytical with the help of SPSS for Windows software. The output of this research explains that perceived organizational support has a significant and positive impact on employee engagement. Self-efficacy has a significant and positive impact on employee engagement. The work environment has a significant and positive impact on employee engagement. Perceived organizational support, self-efficacy, and work environment together have a significant impact on employee engagement. Research implication that can be applied to companies is that companies need to give awards to employees who perform well. The company can provide education, training and development regularly to employees. Leaders need to impose sanctions on employees who do not wear Personal Protective Equipment. Companies also need to provide clinics or health vehicles such as ambulances to anticipate more fatal emergency events. Companies can hire motivator services to provide material and guidance to be more enthusiastic, proud, and engaged with the company.
\end{abstract}

Keywords: employee engagement; perceived organizational support; self efficacy; work environment.

\section{PENDAHULUAN}

Perkembangan industri yang semakin pesat ditandai dengan terciptanya era revolusi industri 4.0 membuat suatu perubahan yang cukup berpengaruh besar terhadap segala sektor yang berkaitan dengan kegiatan industri. Sumber daya manusia menjadi satu di antara sebab kunci guna mencapai tujuan organisasi. Sumber daya manusia yang berkualitas dan memiliki efektivitas kerja tinggi merupakan salah satu cara perusahaan dalam upaya meningkatkan keberhasilan dan produktivitasnya. Peran sumber daya manusia sangatlah vital bagi keberlangsungan perusahaan. Di mana pengelolaan sumber daya manusia yang baik merupakan fondasi awal bagi perusahaan dalam membantu merealisasikan program dan tujuan perusahaan agar dapat tercapai dengan optimal (Abadi et al., 2020).

Pentingnya peran sumber daya manusia yang berkualitas menjadi suatu dorongan dan motivasi tersendiri bagi perusahaan agar memberikan segala sesuatu yang dibutuhkan oleh karyawan sehingga karyawan tersebut dapat terikat (Tabak \& Hendy, 2016). Priambodo et al. (2019) menyatakan ada $36 \%$ karyawan di Indonesia yang mengalami kondisi sangat terikat (engaged) dan 17\% karyawan tidak terikat (not engaged) yang dapat memunculkan risiko melemahnya produktivitas serta kinerja karyawan. Di samping itu, 23\% lainnya digolongkan sebagai karyawan yang hampir terikat karena merasa tidak mendapatkan support saat bekerja. Sisanya digolongkan dalam kelompok yang memisahkan diri. Karyawan yang terikat (engaged) tentunya akan memberikan kontribusi maksimal serta mengerahkan dedikasi, waktu, tenaga, pikiran dan seluruh sumber daya yang dimilikinya untuk kejayaan perusahaan (Agu, 2015). 
David Yusuf Firnanda \& Dewie Tri Wijayati. Pengaruh Perceived Organizational Support, Self Efficacy, dan Lingkungan Kerja terhadap Employee Engagement Karyawan PT. Pesona Arnos Beton

Perceived Organizational Support (POS) mencerminkan jenis dukungan organisasi yang berkembang melalui interaksi antara karyawan dengan agen organisasi seperti supervisor/atasan, POS juga mencerminkan keyakinan pada diri karyawan tentang tolok ukur perusahaan menilai kinerja maupun simpati dengan kesejahteraan karyawan (Yongxing et al., 2017). Ketika perusahaan memberikan dukungannya secara maksimal kepada karyawan, maka karyawan akan membalas dukungan tersebut dengan kerja keras, memberikan seluruh tenaga dan pikirannya pada pekerjaan serta meningkatkan kinerja. Karyawan juga akan semakin percaya diri dalam bekerja, semakin tinggi persepsi dukungan organisasi maka akan semakin tinggi pula self efficacy dan engagement pada karyawan (Purwaningtyas \& Septyarini, 2021).

Penelitian terdahulu yang relevan dengan pernyataan di atas dilakukan oleh Fouzia et al. (2018), Biswas \& Bhatnagar (2013), Caesens \& Stinglhamber (2014), Alvi et al. (2014), Köse (2016), Tabak \& Hendy (2016), dan Imran et al. (2020) menyatakan jika ada dampak positif dan signifikan di antara POS dan employee engagement. Namun, Nusatria (2011) menyatakan tidak ada pengaruh POS terhadap employee engagement. Penelitian lain juga menemukan hubungan antara POS dan self efficacy, seperti penelitian yang dilakukan Purwaningtyas \& Septyarini (2021), Rockow et al. (2016), Zheng et al. (2018), Ozkoc \& Bektas (2016) menyatakan bahwa terdapat pengaruh positif dan signifikan antara variabel POS dan self efficacy.

Self efficacy berpotensi dapat meningkatkan engagement karyawan, kepuasan kerja, gaya belajar, dan peningkatan kinerja (Chaudhary et al., 2013). Self efficacy didefinisikan sebagai kepercayaan dan keyakinan diri individu atas kemampuannya untuk bisa bekerja dengan maksimal sehingga mampu memeroleh suatu keberhasilan (Trilolita et al., 2017). Self efficacy sangat diperlukan pada diri individu karyawan, karena dengan meningkatkan kemampuan dan kepercayaan dalam mengerjakan tugas-tugas yang diberikan oleh perusahaan, maka perusahaan akan berjalan dengan optimal dan kinerja karyawan akan mengalami peningkatan. Karyawan juga akan merasa terikat dengan pekerjaanya karena secara sadar dan bertanggung jawab karyawan akan memberikan segala yang dimiikinya untuk kemajuan perusahaan (Agu, 2015).

Hegarty (2015), Trilolita et al. (2017), Sarinah \& Prasadja (2018), Priambodo et al. (2019), Carter et al. (2018), Chaudhary et al. (2013), dan Chen (2016) menyatakan terdapat pengaruh positif secara langsung antara self efficacy dan employee engagement. Namun hal berbeda ditemukan Liu et al. (2017), Chan et al. (2017) dan Pristiwiana \& Syihabudhin (2020) bahwa self efficacy tidak berdampak signifikan terhadap employee engagement.

Lingkungan kerja menjadi satu di antara sebab utama yang mesti dinilai dari organisasi agar karyawan dapat bekerja dengan nyaman (Hanaysha, 2016). Menurut Suwondo \& Sutanto (2015) lingkungan kerja menjadi sebuah wadah karyawan berproses yang di dalamnya terdapat seluruh fasilitas baik sarana dan prasarana atau segala sesuatu yang mendukung kinerja karyawan. Ketika kondisi lingkungan kerja dirasa cukup kondusif dan memadai maka produktivitas karyawan meningkat, tingkat stress dan konflik akan berkurang, kepuasan kerja meningkat, meningkatkan komitmen di antara karyawan serta karyawan akan lebih terikat dengan pekerjaannya (Razak et al., 2016). Kondisi lingkungan kerja yang baik juga akan mendorong karyawan untuk lebih percaya diri bahwa mereka mampu untuk menyelesaikan tugas sesuai dengan kemampuannya (Rofiana, 2014).

Chaudhry et al. (2017), Kumar \& Sia (2012), Mohd et al. (2016), Anitha (2014), Pringgabayu \& Kusumastuti (2016), dan Setiyani et al. (2019) mengatakan adanya dampak signifikan dan positif di antara lingkungan kerja dengan employee engagement. Berbeda dengan Nasidi et al. (2019), output penelitiannya menunjukkan terdapat korelasi yang tidak signifikan di antara lingkungan kerja dengan employee engagement. Penelitian lain juga menemukan adanya pengaruh signifikan dan positif antara lingkungan kerja dan self efficacy (Rofiana, 2014; Saputri \& Lestariningsih, 2021; Sutaji et al., 2019; dan Tyas \& Nurhasanah, 2019)

Penelitian dilakukan di PT. Pesona Arnos Beton, perusahaan yang bergerak dalam bidang produksi beton dengan aneka produk olahan beton seperti box culvert, udith, precast, pagar panel, LPC, top- 
bottom, dan paving yang didirikan pada tanggal 16 November 2016. Hasil pengamatan menunjukkan masih terdapat karyawan yang kurang bersemangat dan antusias serta kurang menikmati pekerjaannya. Karyawan juga merasa tidak betah berlama-lama dalam bekerja. Berdasarkan wawancara dengan HR Management PT. Pesona Arnos Beton mengungkapkan bahwa masih banyak karyawan yang malas dalam bekerja. Hal ini menunjukkan kurangnya tingkat employee engagement pada karyawan. Hal tersebut dapat terjadi karena beberapa faktor yakni karyawan masih belum merasakan dukungan dari perusahaan dalam menghargai kontribusi mereka. Hasil pengamatan menemukan tidak adanya fasilitas untuk menyampaikan pendapat maupun keluhan yang dialami oleh karyawan. Karyawan pun merasa sungkan dan takut apabila menyampaikan pendapat atau keluhannya secara langsung pada atasan. Tidak adanya reward tersendiri bagi karyawan selain bonus yang diberikan pada saat menerima gaji. Karyawan juga sulit dalam mendapatkan promosi jabatan ke jenjang karir yang lebih tinggi karena minimnya kesempatan yang diberikan perusahaan bagi karyawan untuk mengembangkan karir. Rasa efikasi diri dari karyawan pun masih kurang. Hasil wawancara menunjukkan jika karyawan merasa kurang percaya diri terhadap hasil pekerjaannya karena ditakutkan ada kesalahan saat bekerja sehingga produk yang dihasilkan cacat atau tidak sesuai. Beberapa karyawan juga masih belum bisa mengendalikan hal-hal yang diperlukan dalam menyelesaikan tugas. Kondisi lingkungan tempat kerja di PT. Pesona Arnos Beton dapat dikatakan kurang kondusif, karena tempat kerja sangat berdebu akibat material pembuatan beton. Suara bising mesin terdengar sangat keras dan mengganggu. Kondisi ruang kerja di kantor juga kurang bersahabat, terdapat beberapa pendingin ruangan yang mati membuat udara semakin panas. Layout dalam kantor juga kurang nyaman bagi sebagian karyawan karena tidak memiliki sekat pembatas antara satu dengan yang lain. Di dalam perusahaan juga tidak tersedia fasilitas kesehatan seperti klinik. Banyak karyawan yang tidak menggunakan alat pelindung diri seperti helm, sepatu, sarung tangan, dan masker dalam bekerja padahal perusahaan telah menyediakan fasilitas Alat Pelindung Diri (APD) tersebut kepada setiap karyawan.

Penelitian ini bertujuan untuk menguji dan menganalisis adanya pengaruh perceived organizational support, self efficacy, dan lingkungan kerja terhadap employee engagement karyawan PT. Pesona Arnos Beton.

\section{KAJIAN PUSTAKA DAN PENGEMBANGAN HIPOTESIS}

\section{Perceived Organizational Support (POS)}

Caesens \& Stinglhamber (2014) mengartikan Perceived Organizational Support (POS) menjadi suatu anggapan pekerja yang berorientasi ke rasa yakin seberapa jauh perusahaan atau organisasi menilai kinerja, memberi dukungan, dan simpati terhadap kesejahteraan pekerja. Menurut Danish et al. (2013) POS merupakan suatu harapan dari karyawan tentang bagaimana organisasi menilai kinerja. Motivasi perusahaan yang diperoleh pekerja memiliki dampak vital utamanya untuk organisasi juga untuk karyawan itu sendiri. Hal tersebut memungkinkan karyawan untuk merasa aman dan merasa bahwa ada kekuatan organisasi yang senantiasa mendukung mereka dari belakang (Köse, 2016). POS tidak hanya menjamin karyawan tentang sumber daya ekstrinsik seperti gaji dan tunjangan, tetapi juga memastikan adanya dukungan nyata dari organisasi, keyakinan, penghargaan, dan status (Biswas \& Bhatnagar, 2013). Selain itu, perusahaan juga perlu mendukung karyawan ketika sedang berada dalam masalah atau kesulitan, senantiasa menjaga komunikasi, dan memahami apa yang dibutuhkan oleh karyawan untuk meningkatkan skillnya (Hoa et al., 2020). Ketika karyawan merasakan adanya dukungan dari organisasi yang mengalir, maka karyawan akan menunjukkan perilaku yang dapat membantu dan memercepat tercapainya tujuan organisasi (Mujiasih, 2015). POS juga dianggap dapat memengaruhi karyawan secara psikologis dengan semakin meningkatkan rasa kewajiban untuk peduli terhadap keberhasilan perusahaan serta meningkatkan harapan dari karyawan bahwa kinerja mereka sangat dihargai (Mayes et al., 2017).

\section{Self Efficacy}

Menurut Trilolita et al. (2017) self efficacy ialah suatu kepercayaan dalam diri individu yang muncul karena didasarkan oleh keyakinan diri atas kemampuan yang dimiliki oleh individu dalam 
David Yusuf Firnanda \& Dewie Tri Wijayati. Pengaruh Perceived Organizational Support, Self Efficacy, dan Lingkungan Kerja terhadap Employee Engagement Karyawan PT. Pesona Arnos Beton

menjalankan suatu tugas atau pekerjaan sehingga mampu memeroleh keberhasilan. Sarinah \& Prasadja (2018) menyatakan self efficacy sebagai salah satu aspek dalam diri individu yang secara umum berhubungan dengan durabilitas diri, kemampuan dalam mengendalikan diri dan mencapai tujuan, kemampuan dalam menghadapi tantangan serta ketekunan dalam menghadapi rintangan sehingga memicu kepuasan dalam diri individu. Dengan membangun sikap self efficacy yang baik tentunya akan menciptakan sumber daya psikologis yang berperan besar dalam memengaruhi persepsi dan interpretasi karyawan tentang pekerjaan yang mereka lakukan (Chan et al., 2017). Faktor eksternal seperti keluarga, teman dekat, orang tua dan masyarakat lingkungan sekitar juga dapat memperkuat self efficacy selain dari faktor internal seperti sifat pribadi individu (Fazlurrahman, 2020). Di lingkungan kerja, hal ini dapat menghasilkan produktivitas serta perasaan sejahtera yang lebih besar dalam diri kayawan (Hegarty, 2015). Namun, karyawan yang memiliki tingkat self efficacy yang rendah akan cenderung berpikiran bahwa tugas dan masalah yang dihadapi dalam bekerja akan senantiasa tampak lebih sulit dari kenyataan yang sebenarnya ada di lapangan (Surjanti et al., 2020).

\section{Lingkungan Kerja}

Menurut Sutrisno (2009) lingkungan kerja merupakan suatu keseluruhan kebutuhan sarana prasarana yang ada di sekitar perusahaan yang dapat memengaruhi karyawan dalam melakukan pekerjaannya. Sarana dan prasarana tersebut meliputi berbagai kondisi lingkungan yang terjadi di tempat kerja. Tak hanya kondisi sarpras saja, kondisi fisik dan psikis karyawan juga harus diperhatikan karena penting untuk memastikan bahwa karyawan memiliki suasana hati yang baik dalam bekerja (Elqadri et al., 2016). Setiap melaksanakan tugas, karyawan dapat senantiasa berkomunikasi dengan bermacammacam situasi yang ada di lingkungan tempat mereka bekerja (Pringgabayu \& Kusumastuti, 2016). Lingkungan kerja sangat menentukan bagaimana kondisi perusahaan yang mencakup kondisi sosial, psikologis, dan fisik. Perusahaan harus menyiapkan lingkungan yang baik bagi karyawannya untuk bekerja karena hal ini sangat memengaruhi kenyamanan karyawan saat bekerja. Pengaruh dari lingkungan juga menentukan nilai dari pekerjaan yang dilakukan (Setiyani et al., 2019). Oleh karena itu lingkungan kerja memainkan peran yang cukup vital guna menumbuhkan kemampuan pekerja (Mohd et al., 2016). Sageer et al. (2012) menyatakan bahwa karyawan akan sangat terpacu serta merasa puas, senang, aman, nyaman dan santai karena mendapati kondisi lingkungan kerja mereka yang baik.

\section{Employee Engagement}

Menurut Gallup (2013) employee engagement adalah suatu keterlibatan karyawan yang terikat penuh dengan pekerjaan dan organisasi. Employee engagement merupakan suatu sikap psikologis yang positif bagi karyawan untuk memberdayakan kondisi kerja agar perusahaan dapat merasakan efektivitas kerja yang lebih besar serta dapat berkontribusi dalam meningkatkan produktivitas perusahaan (Sarinah \& Prasadja, 2018). Jha \& Kumar (2016) menyatakan bahwa karyawan yang engaged adalah seseorang yang memahami perannya masing-masing, memiliki hubungan dan komitmen yang kuat untuk perusahaan, lebih berusaha keras untuk mempelajari hal-hal baru, memiliki semangat untuk sukses dan lain-lain. Employee engagement merupakan hal yang vital untuk perusahaan dan juga menjadi salah satu elemen kunci untuk mencapai keberhasilan organisasi (Chiemeke et al., 2019). Sementara itu, menurut Fazlurrahman et al. (2020) karyawan yang terikat dalam pekerjaan akan selalu bersemangat, bangga menjadi bagian dari perusahaan, bahagia dan senang dengan apa yang dilakukan, serta memiliki rasa kepuasan tersendiri dalam pekerjaannya.

\section{Hubungan antar Variabel}

Berdasarkan teori dari para ahli dan penelitian terdahulu di atas, maka fokus penelitian ini adalah membuktikan pengaruh dari perceived organizational support, self efficacy dan lingkungan kerja terhadap employee engagement. Kerangka konseptualnya ditunjukkan pada gambar 1. 


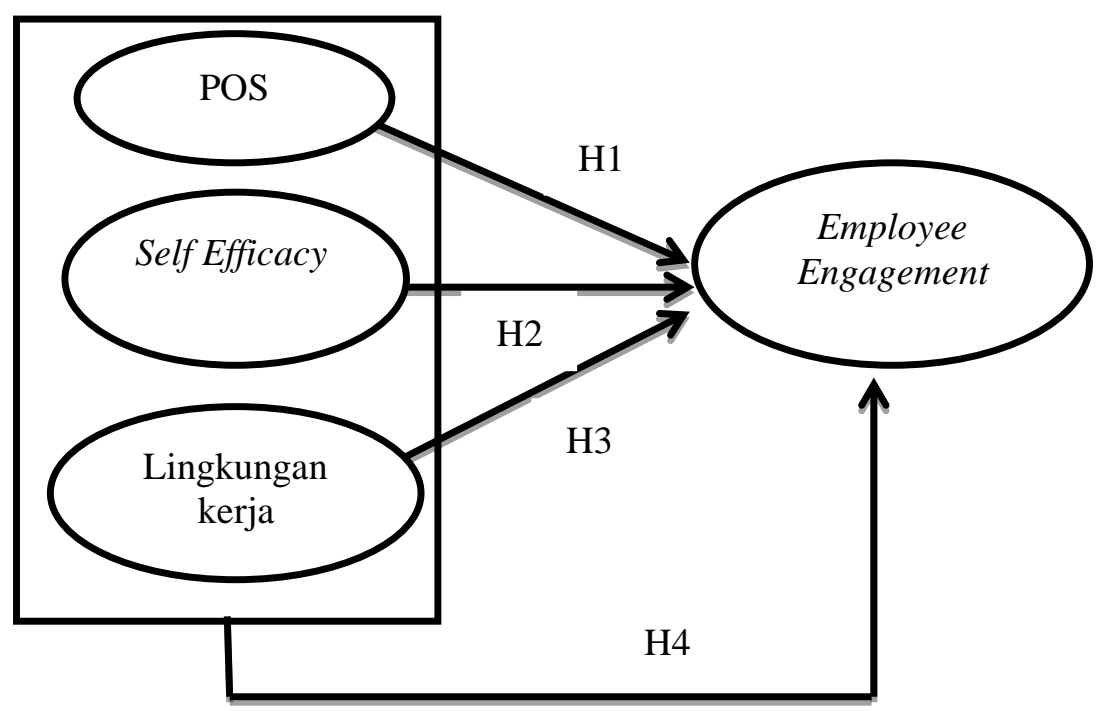

Sumber: Data diolah penulis (2021)

Gambar 1. KERANGKA KONSEPTUAL

POS dianggap sebagai sebuah dukungan atau bantuan dari perusahaan yang dibalas oleh karyawan dengan menunjukkan kerja terbaiknya (Muhammad, 2014). Jika sebuah perusahaan memberikan pelatihan, sumber daya, dan dukungan yang memadai, maka para karyawan pun akan merasa engaged dan ingin perusahaannya berhasil (Miao, 2011). Dukungan organisasi yang dirasakan dapat meningkatkan kinerja yang terkait pekerjaan serta efektifitas dalam bekerja yang berkelanjutan (Karatepe, 2012). POS juga dapat memengaruhi karyawan secara positif dengan meningkatkan minat dalam tugas dan pekerjaan yang dilakukan (Fouzia et al., 2018). Karyawan dengan tingkat POS yang besar dapat menjadi lebih engaged dalam pekerjaan dan organisasi, sehingga dapat membantu perusahaan dalam mencapai tujuannya (Imran et al., 2020). Karyawan dengan persepsi dukungan organisasi yang tinggi akan memberikan segala usaha, tenaga, dan pikiran yang mereka miliki untuk mengabdi pada perusahaan, hal ini tentunya akan meningkatkan employee engagement karyawan (Kalidass \& Bahron, 2015). Menurut Caesens \& Stinglhamber (2014) jika bertambah besar perolehan POS pada karyawan, maka tingkat employee engagement pada karyawan juga akan meningkat. Köse (2016) menunjukkan bahwa POS memiliki pengaruh signifikan positif terhadap employee engagement.

H1 : POS berpengaruh signifikan positif terhadap employee engagement.

Self efficacy menjadi suatu sikap yang sangat penting yang seharusnya dimiliki oleh setiap karyawan. Dengan adanya sikap self efficacy yang melekat pada diri karyawan maka setiap pekerjaan akan menjadi mudah karena karyawan memiliki rasa kepercayaan dan keyakinan diri yang tinggi bahwa mereka mampu mengerjakan dan menyelesaikan pekerjaan dengan baik demi tercapainya keberhasilan (Nusannas et al., 2020). Karyawan dengan self efficacy yang kuat akan dapat menciptakan perasaan tenang dan merasa tertantang dalam menghadapi tugas yang sulit (Surjanti et al., 2020). Hal ini tentunya akan membuat karyawan menjadi semakin bersemangat, bangga, antusias, dan puas akan pekerjaannya (Fazlurrahman et al., 2020). Menurut Musenze et al. (2020) self efficacy berkaitan dengan employee engagement karyawan, karena karyawan dengan tingkat self efficacy yang tinggi diharapkan dapat mendorong rasa semangat, dedikasi, dan penyerapan pada diri mereka agar dapat bekerja dengan lebih baik. Oleh karena itu, karyawan yang tingkat self efficacy tinggi akan lebih terikat (engaged) dengan perusahaan (Liu et al., 2017). Sarinah \& Prasadja (2018) menyatakan bahwa terdapat pengaruh langsung dan signifikan antara self efficacy dan employee engagement.

$\mathrm{H} 2$ : Self efficacy berpengaruh signifikan positif terhadap employee engagement. 
David Yusuf Firnanda \& Dewie Tri Wijayati. Pengaruh Perceived Organizational Support, Self Efficacy, dan Lingkungan Kerja terhadap Employee Engagement Karyawan PT. Pesona Arnos Beton

Kondisi kehidupan sosial, fisik, dan psikologis karyawan di tempat kerja sangat ditentukan oleh kondisi lingkungan kerja yang baik dalam perusahaan (Setiyani et al., 2019). Menurut Rahardjo (2014) kondisi lingkungan kerja terutama suasana kerja dapat memengaruhi semangat kerja karyawan. Lingkungan kerja memainkan peran penting mengenai faktor-faktor yang menyebabkan engagement pada karyawan (Kumar \& Sia, 2012). Menurut Agbozo (2017) lingkungan kerja memiliki banyak sifat yang bisa menyebabkan kesejahteraan fisik dan psikis dari para karyawan. Kondisi lingkungan kerja yang bermutu amat vital guna mengoptimalkan karyawan saat mengerjakan bermacam kewajibannya dengan optimal. Apabila karyawan merasa senang dan puas terhadap kualitas kehidupan kerjanya, maka pada akhirnya akan berdampak sangat positif bagi perusahaan. Produktivitas karyawan meningkat, tingkat stres dan konflik akan berkurang, kepuasan kerja meningkat, meningkatkan komitmen di antara karyawan serta karyawan akan lebih terikat dengan perusahaan (Razak et al., 2016). Lingkungan kerja yang baik telah terbukti dapat meningkatkan produktivitas dan engagement karyawan (Esthi, 2021). Pernyataan tersebut didukung oleh Mohd et al. (2016) menyatakan lingkungan kerja berpengaruh positif dan signifikan terhadap employee engagement.

\section{H3 : Lingkungan kerja berpengaruh signifikan positif terhadap employee engagement.}

Employee engagement merupakan suatu keadaan di mana karyawan menggunakan juga menunjukkan emosi mereka secara fisik, kognitif dan emosional saat bekerja yang ditandai dengan semangat, dedikasi, dan pengabdian (Goestjahjanti et al., 2020). Menurut Chiedu \& Ashari (2020) untuk mencapai suatu tingkatan karyawan yang benar-benar engaged tidaklah mudah. Ada banyak faktor yang menyebabkan karyawan menjadi terikat dengan perusahaan. Beberapa faktor di antaranya adalah faktor kondisi emosional dan psikologis karyawan haruslah dalam kondisi baik serta mendukung segala hal yang berkaitan dengan pekerjaan dan pengalaman kerja mereka. POS, Self Efficacy, dan Lingkungan kerja merupakan tiga hal dari beberapa faktor yang dapat mendukung dan menciptakan karyawan yang engaged baik dalam pekerjaan maupun perusahaan. Apabila ketiga hal tersebut telah dimiliki dan dipenuhi, maka karyawan dengan senang hati akan berkerja secara maksimal untuk mencapai keberhasilan perusahaan. Ozkoc \& Bektas (2016) menyatakan bahwa terdapat pengaruh positif dan signifikan antara variabel POS dan self efficacy. Tyas \& Nurhasanah (2019) menyatakan adanya pengaruh signifikan dan positif antara lingkungan kerja dan self efficacy. Chaudhry et al. (2017) mengatakan adanya dampak signifikan dan positif di antara lingkungan kerja dengan employee engagement. Carter et al. (2018) menyatakan terdapat pengaruh positif secara langsung antara self efficacy dan employee engagement. Fouzia et al. (2018) menyatakan jika ada dampak positif dan signifikan di antara POS dan employee engagement.

H4 : POS, self efficacy, dan lingkungan kerja secara bersama-sama berpengaruh signifikan positif terhadap employee engagement.

\section{METODE PENELITIAN}

Penelitian ini menggunakan teknik penelitian kuantitatif. Teknik pengumpulan data memakai metode observasi, wawancara, dan penyebaran kuisioner. Skala pengukuran memakai skala Likert 1-5. Lokasi penelitian ini dilakukan pada PT. Pesona Arnos Beton yang beralamat di JL. Raya Kedamean, Desa Banyu Urip 05/01, Kecamatan Kedamean, Kabupaten Gresik, Jawa Timur 61175. Teknik sampling pada penelitian ini ialah teknik sampel jenuh di mana seluruh karyawan PT. Pesona Arnos Beton sebanyak 80 orang menjadi responden. Analisis data menggunakan analisis Regresi Linier Berganda dengan software SPSS for windows. Variabel POS, indikator yang digunakan merujuk pada Chiang \& Hsieh (2012) yaitu organisasi peduli dengan pendapat karyawan, organisasi peduli dengan kesejahteraan karyawan, organisasi memerhatikan nilai dan tujuan karyawan, organisasi bersedia membantu karyawan ketika memiliki masalah, dan organisasi akan memaafkan kesalahan yang dilakukan karyawan dalam pekerjaan. Indikator self efficacy merujuk pada Pristiwiana \& Syihabudhin (2020) yakni magnitude (level), strenght, dan generality. Variabel lingkungan kerja merujuk indikator dari Naa (2017) yaitu suasana kerja, tersedianya fasilitas untuk karyawan, dan hubungan dengan 
sesama rekan kerja. Employee engagement merujuk indikator dari Chan et al. (2017) yakni vigour, dedication, dan absorption.

\section{HASIL DAN PEMBAHASAN}

Proses pengambilan data pada penelitian ini menggunakan metode survei angket/kuisioner pada seluruh kayawan PT. Pesona Arnos Beton yang berjumlah 80 responden. Berikut deskripsi dari masing-masing karakteristik responden yang didasarkan pada jenis kelamin, usia, pendidikan, status, dan masa bekerja.

Jumlah sampel keseluruhan dari penelitian ini berjumlah 80 responden dengan detail pekerja berjenis kelamin laki-laki sejumlah 75 pekerja $(93,8 \%)$ juga pekerja dengan jenis kelamin perempuan sejumlah 5 pekerja $(6,3 \%)$. Jumlah karyawan dengan usia $<30$ tahun adalah sejumlah 12 pekerja (15\%), usia 30-40 tahun sejumlah 42 pekerja (52,5\%), usia 41-50 tahun sejumlah 22 pekerja $(27,5 \%)$, dan karyawan dengan usia $>50$ tahun sejumlah 4 pekerja (5\%). Karyawan dengan pendidikan SLTA sebanyak 70 orang $(87,5 \%)$, Strata 1 (S1) sebanyak 5 orang $(6,3 \%)$, dan karyawan dengan tingkat pendidikan lainnya sebanyak 5 orang $(6,3 \%)$. Kemudian karyawan yang berstatus sudah menikah sebanyak 77 orang $(96,2 \%)$, adapun yang belum menikah sebanyak 3 orang $(3,8 \%)$. Pekerja memiliki masa kerja 0-5 tahun beranggotakan 68 pekerja (85\%) dan pekerja memiliki masa kerja 5-10 tahun beranggotakan 12 pekerja (15\%).

Penelitian ini menggunakan three box method untuk mengetahui nilai rata-rata (mean) dari jawaban responden, di mana nilai paling rendah ialah 1 dan yang paling besar ialah 5. Hasil statistik rata-rata variabel POS menunjukkan nilai rata-rata indikator organisasi peduli dengan pendapat karyawan sebesar 4,45; organisasi peduli dengan kesejahteraan karyawan sejumlah 4,43; organisasi memperhatikan nilai dan tujuan karyawan sejumlah 4,33; organisasi bersedia membantu karyawan ketika memiliki masalah sejumlah 4,48; organisasi akan memaafkan kesalahan yang dilakukan karyawan dalam pekerjaan sejumlah 4,35 dengan mean variabel sejumlah 4,41 yang tergolong pada kategori tinggi. Nilai rata-rata indikator self efficacy sebesar 4,48 untuk magnitude (level), 4,59 untuk strenght, 4,60 untuk generality dengan mean variabel sebesar 4,55 yang termasuk dalam kategori tinggi. Mean indikator dari variabel lingkungan kerja untuk suasana kerja sebesar 4,35; tersedianya fasilitas untuk karyawan sebesar 4,41; hubungan dengan sesama rekan kerja sebesar 4,55 dengan nilai mean variabel sebesar 4,43 yang tergolong kategori tinggi. Adapun mean indikator employee engagement antara lain vigour sebesar 4,49; dedication sebesar 4,44; absorption sebesar 4,37 dengan mean variabel 4,43 yang termasuk kategori tinggi.

\section{Hasil Uji Validitas dan Reliabilitas}

Uji validitas dan reliabilitas dilakukan untuk mengetahui apakah item-item pernyataan pada instrumen penelitian yang diukur telah valid dan reliabel. Berdasarkan hasil olah data uji validitas diperoleh koefisien korelasi ( $\mathrm{r}$ hitung) pada semua variabel lebih besar dari pada nilai kritis ( $\mathrm{r}$ tabel $=0,217$ ). Item pernyataan pada instrumen penelitian atau angket yang dipakai pada penelitian ini adalah valid. Pada uji reliabilitas, Cronbach's Alpha dari tiap-tiap variabel memiliki nilai >0,70 yang berarti item pernyataan dari semua variabel dinyatakan reliabel.

\section{Hasil Uji Asumsi Klasik}

Persyaratan uji regresi linier berganda, sebelumnya dilakukan uji normalitas, uji mutikolinieritas, dan uji heterokedastisitas. Uji normalitas menggunakan statistic nonparametic Kolmogorov-Sminornov (K-S) dengan hasil asymp sig. (2-tailed) sejumlah 0,821 > 0,05. Maka bisa dinyatakan data berdistribusi normal. Uji multikolinieritas menunjukkan hasil nilai tolerance dari variabel POS $(0,435)>0,10$; variabel self efficacy $(0,793)>0,10$; variabel lingkungan kerja $(0,447)>0,10$ yang artinya tidak ada multikolinieritas antar variabel bebas. Nilai VIF variabel POS $(2,301)<10$; self efficacy $(1,262)<10$; dan lingkungan kerja $(2,237)<10$. Di mana ketiga variabel memiliki nilai VIF $<10$ maka tidak ada multikolinieritas. Uji heterokedastisitas menggunakan Spearman's rho yang menunjukkan nilai signifikansi pada variabel POS sebesar 0,631; variabel self efficacy sebesar 0,652; 
David Yusuf Firnanda \& Dewie Tri Wijayati. Pengaruh Perceived Organizational Support, Self Efficacy, dan Lingkungan Kerja terhadap Employee Engagement Karyawan PT. Pesona Arnos Beton

dan variabel lingkungan kerja sebesar 0,761 . Hasil pada masing-masing variabel menunjukkan nilai residual lebih besar dari 0,05 , artinya tidak terjadi heterokedastisitas.

\section{Hasil Uji Kelayakan Model}

Berdasarkan hasil analisis diketahui nilai $R=0,857$ dan nilai $R$ Square $\left(R^{2}\right)=0,734$. Nilai tersebut menjelaskan seberapa besar kontribusi dari variabel perceived organizational support, self efficacy, dan lingkungan kerja terhadap variabel employee engagement. Hasil $R^{2}$ sejumlah $0,734=73,4 \%$ menunjukkan bahwa perceived organizational support, self efficacy, dan lingkungan kerja berdampak pada employee engagement karyawan di PT. Pesona Arnos Beton sebesar 73,4\%. Sementara itu, $26,6 \%$ sisanya disebabkan oleh variabel lain di luar variabel yang diteliti.

\section{Hasil Uji Analisis Regresi Linier Berganda}

Penggunaan analisis regresi linier berganda bertujuan mencari tahu dampak dari variabel terikat employee engagement (Y) terhadap variabel bebas perceived organizational support (X1), self efficacy (X2) dan lingkungan kerja (X3). Hasil uji analisis regresi linier berganda pada tabel 1.

\section{Tabel 1. \\ HASIL UJI REGRESI LINIER BERGANDA}

\begin{tabular}{cccc}
\hline Variabel & Koefisien Regresi & Uji t & Signifikansi \\
\hline (Constant) & 0,001 & & \\
POS & 0,187 & 2,920 & 0,005 \\
Self Efficacy & 0,260 & 2,472 & 0,016 \\
Lingkungan Kerja & 0,347 & 6,297 & 0,000 \\
\hline
\end{tabular}

Sumber: output SPSS,diolah (2021)

Berdasarkan tabel 1, maka dapat diperoleh persamaan regresi linier (1).

$\mathrm{Y}=0,001+0,187 \mathrm{X} 1+0,260 \mathrm{X} 2+0,347 \mathrm{X} 3+\mathrm{e}$

Dari tabel 1 dan persamaan (1) dapat dijelaskan bahwa nilai konstanta $(\alpha)$ sebesar 0,001 . Maka dengan adanya perceived organizational support, self efficacy, dan lingkungan kerja yang baik maka nilai employee engagement pada karyawan hanya sebesar 0,001 . Nilai tersebut bertanda positif yang berarti jika karyawan PT. Pesona Arnos Beton tidak merasakan perceived organizational support, self efficacy, dan lingkungan kerja yang sesuai maka karyawan akan tetap engaged dengan nilai 0,001. Nilai koefisien regresi variabel perceived organizational support sebesar 0,187 . Tanda positif pada nilai tersebut menandakan adanya hubungan yang searah, artinya apabila semakin baik perceived organizational support yang ada pada karyawan maka employee engagement pekerja juga akan semakin baik. Koefisien regresi variabel self efficacy sejumlah 0,260. Hasil koefisien bertanda positif menandakan variabel self efficacy dan employee engagement memiliki hubungan yang searah. Hal tersebut berarti semakin baik sikap self efficacy yang dimiiki oleh karyawan maka akan semakin baik pula employee engagement dari para karyawan. Hasil koefisien regresi dari variabel lingkungan kerja ialah 0,347 . Nilai positif artinya terdapat hubungan yang searah. Di mana nilai positif tersebut memiliki makna jika makin baik lingkungan kerja di dalam perusahaan maka makin baik pula employee engagement dari karyawan.

\section{Hasil Uji Hipotesis}

Pada tabel 1, nilai dari uji t ( $\mathrm{t}$ hitung) variabel perceived organizatinal support adalah sejumlah 2,920 dengan hasil signifikansi sejumlah 0,005 $<0,05$. Dari hasil tersebut bisa diketahui jika variabel perceived organizational support berpengaruh signifikan kepada employee engagement. Kemudian diketahui hasil t hitung variabel self efficacy sejumlah 2,472 dengan hasil signifikansi sejumlah 0,016. Nilai signifikansi 0,016 < 0,05 menunjukkan bahwa variabel self efficacy berdampak signifikan kepada variabel employee engagement. Selanjutnya, hasil t hitung dari variabel lingkungan kerja sebesar 6,297 dengan hasil signifikansi $0,000<0,05$. Maka dapat diketahui jika variabel lingkungan 
kerja berdampak signifikan kepada employee engagement. Pada hasil uji $\mathrm{F}$ (simultan) menghasilkan nilai signifikansi sebesar 0,000 . Di mana nilai signifikansi $0,000<0,05$, maka dapat dijelaskan bahwa variabel perceived organizational support, self efficacy, dan lingkungan kerja secara simultan atau secara bersama-sama berpengaruh signifikan terhadap variabel employee engagement.

\section{Pengaruh Perceived Organizational Support (POS) terhadap Employee Engagement}

Hasil pengujian diketahui bahwa POS berpengaruh signifikan positif terhadap employee engagement karyawan PT. Pesona Arnos Beton. Hasil ini menguatkan penelitian Fouzia et al. (2018), Biswas \& Bhatnagar (2013), Caesens \& Stinglhamber (2014), Alvi et al. (2014), Köse (2016), Tabak \& Hendy (2016), dan Imran et al. (2020) yang mengatakan jika perceived organizational support berdampak signifikan positif kepada employee engagement.

Mufarrikhah et al. (2020) mengemukakan bahwa timbulnya perasaan aman, nyaman, bermakna, dan kepuasan dalam bekerja yang dirasakan oleh karyawan tidak terlepas dari adanya dukungan penuh dari organisasi. Menurut Kalidass \& Bahron (2015) persepsi dukungan organisasi yang tinggi akan meningkatkan employee engagement karyawan karena mereka akan memberikan segala usaha, tenaga, dan pikiran yang dimiliki untuk mengabdi pada organisasi.

Penjelasan di atas dapat diperkuat berdasarkan hasil wawancara yang dilakukan terhadap bapak Rusdiantoro selaku HRD. Beliau menyatakan bahwa PT. Pesona Arnos Beton selalu ada di samping karyawan walaupun karyawan tersebut memiliki permasalahan ataupun sedang ditimpa musibah. Perusahaan akan dengan senang hati membantu dengan memberikan berbagai macam bantuan baik materil maupun moril. Perusahaan juga sangat terbuka bagi karyawan yang ingin menyampaikan pendapat mereka secara langsung dengan mengobrol secara tatap muka dengan supervisor/pimpinan. Beberapa hal tersebut secara tidak langsung akan berakibat pada tumbuhnya persepsi dari karyawan bahwa PT. Pesona Arnos Beton sangat mendukung kehidupan kerja mereka.

\section{Pengaruh Self Efficacy terhadap Employee Engagement}

Hasil pengujian menyatakan jika self efficacy memiliki dampak signifikan positif kepada employee engagement karyawan PT. Pesona Arnos Beton. Hasil ini memperkuat penelitian Hegarty (2015), Trilolita et al. (2017), Sarinah \& Prasadja (2018), Priambodo et al. (2019), Carter et al. (2018), Chaudhary et al. (2013), dan Chen (2016) yang mengatakan bahwa self efficacy berdampak signifikan positif kepada employee engagement.

Membangun sikap self efficacy yang baik tentunya akan menciptakan sumber daya psikologis yang berperan besar dalam memengaruhi persepsi dan interpretasi karyawan tentang pekerjaan yang mereka lakukan (Chan et al., 2017). Menurut Fazlurrahman (2020) self efficacy yang tinggi pada karyawan akan membuat karyawan semakin engaged karena karyawan akan menjadi semakin bersemangat, bangga, antusias, dan puas akan pekerjaannya.

Hal tersebut didukung dari hasil tanya jawab dengan karyawan bahwasanya karyawan mampu untuk mengerjakan tugas-tugas dengan baik meskipun sulit. karyawan juga bersedia serta yakin dan mampu apabila disuruh untuk mengerjakan tugas yang tidak sesuai dengan bidangnya dan yakin bisa menghasilkan produk-produk terbaik tanpa ada keraguan dan ketakutan akan terjadi cacat pada produk. Hal ini dapat dilihat dari raut wajah para karyawan yang senantiasa tersenyum dan bahagia seakan-akan tidak ada beban atau kesulitan dalam bekerja.

\section{Pengaruh Lingkungan Kerja terhadap Employee Engagement}

Lingkungan kerja berdampak positif dan signifikan kepada employee engagement karyawan PT. Pesona Arnos Beton. Jadi hipotesis diterima. Penelitian ini mendukung Chaudhry et al. (2017), Kumar \& Sia (2012), Mohd et al. (2016), Anitha (2014), Pringgabayu \& Kusumastuti (2016), dan Setiyani et al. (2019) yang mengatakan jika lingkungan kerja berdampak signifikan positif kepada employee engagement. 
David Yusuf Firnanda \& Dewie Tri Wijayati. Pengaruh Perceived Organizational Support, Self Efficacy, dan Lingkungan Kerja terhadap Employee Engagement Karyawan PT. Pesona Arnos Beton

Menurut Sageer et al. (2012) karyawan akan sangat terpacu serta merasa puas, senang, aman, nyaman dan santai karena mendapati kondisi lingkungan kerja mereka yang baik. Apabila karyawan merasa puas, senang, aman dan nyaman dalam bekerja maka hal tersebut akan meningkatkan employee engagement pada karyawan (Razak et al., 2016).

Hasil tanya jawab dengan karyawan membuktikan bahwa karyawan merasa senang, aman, dan nyaman dengan kondisi lingkungan kerja yang ada di PT. Pesona Arnos Beton. Kondisi lingkungan kerja sudah cukup baik di mana hubungan antar karyawan berlangsung dengan baik dan harmonis begitu pula dengan hubungan dengan atasan. Fasilitas yang diberikan perusahaan juga cukup memadai seperti peralatan-peralatan kerja canggih, kantin, musholla, meskipun belum ada klinik tersendiri tetapi jarak antara perusahaan dengan fasilitas kesehatan umum cukup dekat. Perusahaan juga memberikan fasilitas jaminan kesehatan seperti asuransi dan bpjs. Peralatan penunjang keamanan dan keselamatan kerja juga tersedia seperti helm, masker, dan sepatu.

\section{Pengaruh Perceived Organizational Support, Self Efficacy, dan Lingkungan Kerja terhadap Employee Engagement}

Berdasarkan hasil pengujian, variabel POS, self efficacy, dan lingkungan kerja secara bebarengan berdampak signifikan kepada employee engagement pekerja PT. Pesona Arnos Beton. Hal ini didukung oleh penelitian Zheng et al. (2018) menyatakan terdapat pengaruh positif dan signifikan antara variabel POS dan self efficacy. Saputri \& Lestariningsih (2021) menyatakan adanya pengaruh signifikan dan positif antara lingkungan kerja dan self efficacy. Setiyani et al. (2019) mengatakan adanya dampak signifikan dan positif di antara lingkungan kerja dengan employee engagement. Chen (2016) menyatakan terdapat pengaruh positif secara langsung antara self efficacy dan employee engagement. Biswas \& Bhatnagar (2013) menyatakan jika ada dampak positif dan signifikan di antara POS dan employee engagement.

Dari hasil pengamatan diketahui bahwa karyawan selalu memiliki semangat yang tinggi, tekun dan bersungguh-sungguh guna dapat bekerja dengan optimal untuk memeroleh hasil kerja yang tinggi. Dalam beberapa tahun terakhir, perusahaan telah mendapatkan hasil yang cukup besar akibat dari peningkatan produktivitas karyawan. Hal ini ditunjukkan dengan semakin meningkatnya penjualan dan di percayanya perusahaan dalam menangani proyek-proyek besar dari BUMN maupun swasta. Karyawan juga sangat antusias dalam pekerjaannya apalagi dalam menyambut proyek-proyek baru yang akan mereka kerjakan. Dengan adanya proyek tersebut maka karyawan akan semakin bersemangat dan menikmati pekerjaan mereka, karena karyawan selalu berpersepsi bahwa semakin besar proyek yang akan dikerjakan maka semakin besar pula hasil yang didapat. Nilai-nilai tersebut tidak akan dengan mudah diperoleh tanpa dibarengi dengan niat, usaha, dan kegigihan yang tekun dalam bekerja. Bukan hanya karyawan saja yang harus bekerja maksimal, namun perusahaan juga harus mendukung karyawannya agar supaya dapat bekerja sesuai harapan. Selain dukungan moril maupun materiil dari perusahaan, kondisi kenyamanan dan keamanan karyawan juga harus mendapat perhatian lebih. Perhatian terhadap lingkungan kerja yang baik dan kondusif dapat membuat karyawan semakin nyaman dan betah. Dengan dukungan dari perusahaan, karyawan akan menjadi lebih percaya diri dan yakin dapat memberikan yang terbaik untuk tercapainya tujuan perusahaan.

\section{KESIMPULAN}

Sesuai penelitian dan kajian yang telah dijabarkan maka bisa diberi simpulan berikut ini : (1) Perceived organizational support berpengaruh positif dan signifikan terhadap employee engagement; (2) Self efficacy berpengaruh positif dan signifikan terhadap employee engagement; (3) Lingkungan kerja berpengaruh positif dan signifikan terhadap employee engagement; (4) Perceived organizational support, self efficacy, dan lingkungan kerja secara bersama-sama berpengaruh signifikan terhadap employee engagement.

Hasil penelitian ini memberikan beberapa saran praktis yakni perusahaan perlu memberikan perhatian lebih bagi karyawan yang memiliki kinerja baik dengan memberikan reward/penghargaan tersendiri seperti dengan menempelkan foto karyawan terbaik di majalah dinding perusahaan. Perusahaan dapat 
memberikan edukasi, pelatihan dan pengembangan secara rutin pada karyawan untuk meningkatkan skill dan tingkat self efficacy pada karyawan. Pimpinan perlu memberikan sanksi pada karyawan yang tidak memakai APD karena sangat berisiko dan berbahaya bagi karyawan dan keberlangsungan perusahaan apabila terjadi hal-hal yang tidak diinginkan. Perusahaan juga perlu menyediakan klinik tersendiri di dalam lingkungan perusahaan atau setidaknya dengan menyediakan kendaraan kesehatan seperti ambulans sendiri untuk mengantisipasi kejadian darurat yang lebih fatal. Untuk menjaga agar karyawan tetap engaged dengan perusahaan maka perusahaan bisa menyewa jasa motivator untuk memberikan materi dan bimbingan agar karyawan semakin semangat, antusias, bangga, dan terikat dengan perusahaan.

\section{DAFTAR PUSTAKA}

Abadi, R. R., Nursyamsi, I., \& Syamsuddin, A. R. (2020). Effect of Quality of Work-Life and Employee Engagement Towards Job Satisfaction And Employee Performances At PT . Indofood CBP Sukses Makmur, Tbk . Global Scientific Journal. 8(8), 2527-2539.

Agu, O. L. (2015). Work Engagement, Organizational Commitment, Self Efficacy and Organizational Growth: A Literature Review. Information Impact: Journal of Information and Knowledge Management, 6(1), 14-29.

Alvi, A. K., Abbasi, A. S., \& Haider, R. (2014). Relationship of Perceived Organizational Support and Employee Engagement. Sci.Int.(Lahore), 26(2), 951-954.

Anitha. (2014). Determinants of Employee Engagement and Their Impact on Employee Performance. International Journal of Productivity and Performance Management, 63(3), 308-323. https://doi.org/10.1108/IJPPM-01-2013-0008

Biswas, S., \& Bhatnagar, J. (2013). Mediator Analysis of Employee Engagement: Role of Perceived Organizational Support, P-O Fit, Organizational Commitment and Job Satisfaction. Vikalpa, 38(1), 27-40. https://doi.org/10.1177/0256090920130103

Caesens, G., \& Stinglhamber, F. (2014). The Relationship Between Perceived Organizational Support and Work Engagement: The Role of Self-Efficacy and Its Outcomes. Revue Europeenne de Psychologie Appliquee, 64(5), 259-267. https://doi.org/10.1016/j.erap.2014.08.002

Carter, W. R., Nesbit, P. L., Badham, R. J., Parker, S. K., \& Sung, L. K. (2018). The Effects of Employee Engagement and Self-Efficacy on Job Performance: A Longitudinal Field Study. International Journal of Human Resource Management, 29(17), 2483-2502. https://doi.org/10.1080/09585192.2016.1244096

Chan, X. W., Kalliath, T., Brough, P., O’Driscoll, M., Siu, O.-L., \& Carolyn Timms. (2017). SelfEfficacy and Work Engagement: Testof A Chain Model. International Journal of Manpower. 2(2), 1-38. https://doi.org/10.1108/01437720199400001

Chaudhary, R., Rangnekar, S., \& Barua, M. K. (2013). Engaged Versus Disengaged: The Role of Occupational Self-Efficacy. Asian Academy of Management Journal, 18(1), 91-108.

Chaudhry, N. I., Jariko, M. A., Mushtaque, T., Mahesar, H. A., \& Ghani, Z. (2017). Impact of Working Environment and Training \& Development on Organization. European Journal of Training and Development Studies, 4(2), 33-48.

Chen, I. S. (2016). Examining the Linkage Between Creative Self-Efficacy and Work Engagement: The Moderating Role of Openness to Experience. Baltic Journal of Management, 11(4), 516534. https://doi.org/10.1108/BJM-04-2015-0107 
David Yusuf Firnanda \& Dewie Tri Wijayati. Pengaruh Perceived Organizational Support, Self Efficacy, dan Lingkungan Kerja terhadap Employee Engagement Karyawan PT. Pesona Arnos Beton

Chiang, C. F., \& Hsieh, T. S. (2012). The Impacts of Perceived Organizational Support and Psychological Empowerment on Job Performance: The Mediating Effects of Organizational Citizenship Behavior. International Journal of Hospitality Management, 31(1), 180-190. https://doi.org/10.1016/j.ijhm.2011.04.011

Chiedu, C. K., \& Ashari, H. (2020). Moderating Relationship of Organizational Culture Between Quality of Work Life and Employee Engagement View project. International Business Management. 13(11), 577-586. https://doi.org/10.36478/ibm.2019.577.586

Chiemeke, K. C., Bt Ashari, H., \& Bt Muktar, S. N. (2019). Investigating the Impact of Organizational Policy TowardsQuality of Work Life on Employee Engagement in Manufacturing Company Nigeria. European Journal of Economics and Business Studies, 4(2), 141-152. https://doi.org/10.2478/ejes-2018-0047

Danish, R. Q., Ramzan, S., \& Ahmad, F. (2013). Effect of Perceived Organizational Support and Work Environment on Organizational Commitment; Mediating Role of Self-Monitoring. Advances in Economics and Business, 1(4), 312-317. https://doi.org/10.13189/aeb.2013.010402

Eko Hariyanto, R. P., \& Bawono, dan I. R. (2011). Desain Pelatihan, Dukungan Organisasional, Dukungan Supervisor dan Self Efficacy. Siasat Bisnis, 15, 213-227.

Elqadri, Z. M., Wardoyo, D. T. W., \& Priyono. (2016). The Influence of Motivation and Work Environment of Employees Work Achievement the Office of the District of Sampang Regency Pangarengan. JGEMBR(4), 233-240. www.ikpress.org

Esthi, R. B. (2021). Effect of Compensation, Work Environment and Communication on Employee Performance in Ud. Djaya Listrik and Material. Forum Ekonomi Journal, 23(1), 145-154. https://doi.org/10.2139/ssrn.3828481

Fazlurrahman, H. (2020). Measuring Entrepreneurship Intention With Need for Achievement, Locus of Control, Self-Efficacy, and Readiness Instrument: Business and Engineering Student in Indonesia. International Journal of Management, Innovation \& Entrepreneurial Research, 6(1), 07-14. https://doi.org/10.18510/ijmier.2020.612

Fazlurrahman, H., Wardoyo, D. T. W., Hadi, H. K., Rahman, Z., Nugrohoseno, D., \& Rahman, M. F. W. (2020). Analysis of Work Engagement Measurement at Work From Home Due To The Effect of Covid-19 Pandemic. Technium Social Sciences Journal, 14, 363-375.

Fouzia, H. A., Sayyid, S. R., Ishfaq, A., \& Madiha, R. (2018). Effects of Perceived Organizational Support on Organizational Citizenship Behavior-Sequential Mediation by Well-Being and Work Engagement. Journal of the Punjab University Historical Society, 31(2), 61-71.

Gallup. (2013). State of the Global Workplace: Employee Engagement Insight for Business Leaders Wordwide. New Jersey: Gallup, Inc.

Goestjahjanti, S. F., Novitasari, D., Hutagalung, D., Asbari, M., \& Supono, J. (2020). Impact of Talent Management, Authentic Leadership and Employee Engagement on Job Satisfaction: Evidence from South East Asian Industries. Journal of Critical Reviews, 7(19), 67-88. http://www.jcreview.com/?mno=101983

Hanaysha, J. (2016). Testing the Effects of Employee Engagement, Work Environment, and Organizational Learning on Organizational Commitment. Procedia - Social and Behavioral Sciences, 229, 289-297. https://doi.org/10.1016/j.sbspro.2016.07.139 
Hegarty, E. (2015). Employee Engagement, Self efficacy and Stress: a Correlation Study Moderated by Work Locus of Control. Department of Psychology. 5(2). 112-129. https://doi.org/10.1017/CBO9781107415324.004

Hoa, N. D., Ngan, P. T. H., Quang, N. M., Thanh, V. B., \& Quyen, H. V. T. (2020). An Empirical Study of Perceived Organizational Support and Affective Commitment in the Logistics Industry. Journal of Asian Finance, Economics and Business, 7(8), 589-598. https://doi.org/10.13106/JAFEB.2020.VOL7.NO8.589

Imran, M. Y., Elahi, N. S., Abid, G., Ashfaq, F., \& Ilyas, S. (2020). Impact of Perceived Organizational Support on Work Engagement: Mediating Mechanism of Thriving and Flourishing. Journal of Open Innovation: Technology, Market, and Complexity, 6(3). https://doi.org/10.3390/JOITMC6030082

Jha, B., \& Kumar, A. (2016). Employee Engagement: A Strategic Tool to Enhance Performance. DAWN: Journal for Contemporary Research in Management, 3(2), 21-29. http://search.ebscohost.com/login.aspx?direct=true $\& d b=b t h \& A N=117637764 \&$ site=ehost-live

Kafui Agbozo, G. (2017). The Effect of Work Environment on Job Satisfaction: Evidence from the Banking Sector in Ghana. Journal of Human Resource Management, 5(1), 12. https://doi.org/10.11648/j.jhrm.20170501.12

Kalidass, A., \& Bahron, A. (2015). The Relationship between Perceived Supervisor Support, Perceived Organizational Support, Organizational Commitment and Employee Turnover Intention. International Journal of Business Administration, 6(5), 82-89. https://doi.org/10.5430/ijba.v6n5p82

Karatepe, O. M. (2012). Perceived Organizational Support, Career Satisfaction, and Performance Outcomes: A Study of Hotel Employees in Cameroon. International Journal of Contemporary Hospitality Management, 24(5), 735-752. https://doi.org/10.1108/09596111211237273

Köse, A. (2016). The Relationship between Work Engagement Behavior and Perceived Organizational Support and Organizational Climate. Journal of Education and Practice, 7(27), $42-52$.

Kumar, R., \& Sia, S. K. (2012). Employee Engagement: Explicating the Contribution of Work Environment. Management and Labour Studies, 37(1), 31-43. https://doi.org/10.1177/0258042X1103700104

Liu, J., Cho, S., \& Putra, E. D. (2017). The Moderating Effect of Self-Efficacy and Gender on Work Engagement for Restaurant Employees in the United States. International Journal of Contemporary Hospitality Management, 29(1), 624-642. https://doi.org/10.1108/IJCHM-102015-0539

Mayes, B. T., Finney, T. G., Johnson, T. W., Shen, J., \& Yi, L. (2017). The Effect of Human Resource Practices on Perceived Organizational Support in the People's Republic of China. International Journal of Human Resource Management, 28(9), 1261-1290. https://doi.org/10.1080/09585192.2015.1114768

Miao, R.-T. (2011). Perceived Organizational Support, Job Satisfaction, Task Performance and Organizational Citizenship Behavior in China. Institute of Behavioral and Applied Management., 105-127.

Mohd, I. H., Mohd Shah, M., \& Zailan, N. S. Z. (2016). How Work Environment Affects the Employee Engagement in a Telecommunication Company. BE-ci 2016 : 3rd International 
David Yusuf Firnanda \& Dewie Tri Wijayati. Pengaruh Perceived Organizational Support, Self Efficacy, dan Lingkungan Kerja terhadap Employee Engagement Karyawan PT. Pesona Arnos Beton

Conference on Business and 418-426. https://doi.org/10.15405/epsbs.2016.11.02.37

Mufarrikhah, J. L., Yuniardi, M. S., \& Syakarofath, N. A. (2020). Peran Perceived Organizational Support terhadap Work Engagement Karyawan. Gadjah Mada Journal of Psychology (GamaJoP), 6(2), 151-164. https://doi.org/10.22146/gamajop.56396

Muhammad, A. H. (2014). Perceived Organizational Support and Organizational Citizenship Behavior: The Case of Kuwait. International Journal of Business Administration, 5(3), 59-72. https://doi.org/10.5430/ijba.v5n3p59

Mujiasih, E. (2015). Hubungan antara Persepsi Dukungan Organisasi (Perceived Organizational Support) dengan Keterikatan Karyawan. Jurnal Psikologi Undip, 14(1), 40-51. https://doi.org/10.14710/jpu.14.1.40-51

Musenze, I. A., Mayende, T. S., Wampande, A. J., Kasango, J., \& Emojong, O. R. (2020). Mechanism between Perceived Organizational Support and Work Engagement: Explanatory Role of SelfEfficacy. Journal of Economic and Administrative Sciences, 15(10). 234-259.. https://doi.org/10.1108/jeas-02-2020-0016

Naa, A. (2017). Pengaruh Lingkungan Kerja, Motivasi Kerja dan Pelatihan terhadap Kinerja Pegawai di Kantor Distrik Bintuni Kabupaten Teluk Bintuni. Jurnal Renaissance, 2(02), 167-176. http://www.ejournal-academia.org/index.php/renaissance

Nasidi, Y., Makera, A. U., Kamaruddeen, A. M., \& Jemaku, I. M. (2019). Assessing the Impact of Work Environment on Employee Engagement among Non-Academic Staff of the University. SEISENSE Journal of Management, 2(1), 57-68. https://doi.org/10.33215/sjom.v2i1.84

Nusannas, I. S., Yuniarsih, T., Sojanah, J., Mutmainnah, D., \& Imbari, S. (2020). The Effect of SelfEfficacy and Employee Engagement on Employee Performance in Mediation by Digital Literation. Enrichment: Journal of Management. 11(1), 63-67.

Nusatria, S. (2011). Employee Engagement: Anteseden dan Konsekuensi: Studi pada unit CS PT. Telkom Indonesia Semarang. Thesis. Jurusan Manajemen. Fakultas Ekonomi Universitas Diponegoro.

Oren, L., Tziner, A., Nahshon, Y., \& Sharoni, G. (2013). Relations between OCBs, Organizational Justice, Work Motivation and Self-Efficacy. Amfiteatru Economic Journal, 15(34), 505-517. http://hdl.handle.net/10419/168796

Ozkoc, A. G., \& Bektas, T. (2016). Organizational Support and Self-Efficacy as the Predictors of Dissenter Behavior among Hotel Employees. International Journal of Academic Research in Business and Social Sciences, 6(5), 285-305. https://doi.org/10.6007/ijarbss/v6-i5/2143

Priambodo, E. P., Darokah, M., \& Diah Sari, R. E. Y. (2019). Peran Self Efficacy dan Iklim Organisasi dalam membentuk Employee Engagement melalui Komitmen Organisasi. Psympathic : Jurnal Ilmiah Psikologi, 6(2), 213-228. https://doi.org/10.15575/psy.v6i2.4974

Pringgabayu, D., \& Kusumastuti, D. (2016). Peningkatan Keterkaitan Karyawan melalui Sistem Rekrutmen, Desain Pekerjaan, Kompensasi dan Iklim Organisasi dengan Lingkungan Kerja sebagai Variabel Moderasi. Bina Ekonomi, 20(2), 141-162. https://doi.org/10.26593/be.v20i2.2307.141-162

Pristiwiana, O., \& Syihabudhin. (2020). The Effect of Work Environment on Work Engagement with Self Efficacy As Moderator Variable at Hotel Pelangi Malang Employees. International 
Conference on Islam, Economy, and Halal Industry. 364-378. https://doi.org/10.18502/kss.v4i9.7337

Purwaningtyas, E., \& Septyarini, E. (2021). Pengaruh Stres Kerja dan Persepsi Dukungan Organisasi terhadap Produktivitas Karyawan yang di Mediasi oleh Self-Efficacy (Studi Pada Karyawan My Creative.Id Yogyakarta). J-MAS (Jurnal Manajemen Dan Sains), 6(1), 226. https://doi.org/10.33087/jmas.v6i1.248

Rahardjo, S. (2014). The Effect of Competence, Leadership and Work Environment Towards Motivation and its Impact on the Performance of Teacher of Elementary School in Surakarta City , Central JAVA, Indonesia. International Journal of Advanced Research in Management and Social Sciences, 3(6), 59-74. http://www.garph.co.uk/IJARMSS/June2014/7.pdf

Razak, N. A., Ma'amor, H., \& Hassan, N. (2016). Measuring Reliability and Validity Instruments of Work Environment Towards Quality Work Life. Procedia Economics and Finance, 37(16), 520-528. https://doi.org/10.1016/s2212-5671(16)30160-5

Rockow, S., Kowalski, C. L., Chen, K., \& Smothers, A. (2016). Self-efficacy and Perceived Organizational Support by Workers in a Youth Development Setting. Journal of Youth Development, 11(1), 35-48. https://doi.org/10.5195/jyd.2016.432

Rofiana. (2014). Analisis Pengaruh Locus of Control dan Lingkungan Kerja terhadap Kinerja Pegawai dengan Self Efficacy sebagai Mediasi. Jurnal Telaah Manajemen, 11(1), 145-157.

Sageer, A., Agawal, P., \& Rafat, S. (2012). Identification of Variables Affecting Employee Satisfaction and Their Impact on the Organization. IOSR Journal of Business and Management, 5, 32-39. https://doi.org/10.9790/487X-0513239

Saputri, E. A., \& Lestariningsih, M. (2021). Pengaruh Kompetensi dan Self Efficacy terhadap Kinerja Pegawai melalui Lingkungan Kerja Map Fashion Tunjungan Plaza Surabaya. Jurnal Ilmu Dan Penelitian Manajemen, 10(3).

Sarinah, A. M., \& Prasadja, R. (2018). The Effect of Work Autonomy, Self-Efficacy and Work Engagement towards Organizational Commitment. International Journal of Economics, Commerce and Management United Kingdom, VI(2), 31-44. http://ijecm.co.uk/

Setiyani, A., Djumarno, D., Riyanto, S., \& Nawangsari, L. C. (2019). The Effect of Work Environment on Flexible Working Hours, Employee Engagement and Employee Motivation. International Review of Management and Marketing, 9(3), 112-116. https://doi.org/10.32479/irmm.8114

Surjanti, J., Soejoto, A., Seno, D. N., \& Waspodo. (2020). Mangrove Forest Ecotourism: Participatory Ecological Learning and Sustainability of Students' Behavior through Self-Efficacy and SelfConcept. Social Sciences \& Humanities Open, 2(1), 100009. https://doi.org/10.1016/j.ssaho.2019.100009

Sutaji, K., Akbar, M., \& Matin. (2019). Pengaruh Lingkungan Kerja dan Self Efikasi Terhadap Efektifitas Kerja Guru SMP Negeri di Kecamatan Bekasi Utara. Jurnal Visipena, 10(1), 135147.

Sutrisno, E. (2009). Manajemen Sumber Daya Manusia. Jakarta: Kencana.

Suwondo, D. I., \& Sutanto, E. M. (2015). Hubungan Lingkungan Kerja, Disiplin Kerja, dan Kinerja Karyawan. Jurnal Manajemen Dan Kewirausahaan, 17(2), 135-144. https://doi.org/10.9744/jmk.17.2.135-144 
David Yusuf Firnanda \& Dewie Tri Wijayati. Pengaruh Perceived Organizational Support, Self Efficacy, dan Lingkungan Kerja terhadap Employee Engagement Karyawan PT. Pesona Arnos Beton

Tabak, F., \& Hendy, N. T. (2016). Work Engagement: Trust as A Mediator of the Impact of Organizational Job Embeddedness and Perceived Organizational Support. Organization Management Journal, 13(1), 21-31. https://doi.org/10.1080/15416518.2015.1116968

Trilolita, V., Siti A, E., \& Cahyo, M. (2017). Pengaruh Self-Efficacy terhadap Employee Engagement dan Kinerja Karyawan ( Studi pada Karyawan PT Telekomunikasi Indonesia Regional V Surabaya ). Jurnal Administrasi Bisnis, 52(1).

Tyas, A. A. W. P., \& Nurhasanah, N. (2019). Model Keterkaitan Lingkungan Kerja, Kompetensi , terhadap Keterikatan Kerja melalui Self Efficacy di Balitbang Kementrian Hukum dan HAM RI. Conference Paper, November.

Yongxing, G., Hongfei, D., Baoguo, X., \& Lei, M. (2017). Work Engagement and Job Performance: the Moderating Role of Perceived Organizational Support. Anales de Psicologia, 33(3), 708713. https://doi.org/10.6018/analesps.33.3.238571

Zheng, Y., Wang, J., Doll, W., Deng, X., \& Williams, M. (2018). The Impact of Organisational Support, Technical Support, and Self-Efficacy on Faculty Perceived Benefits of Using Learning Management System. Behaviour and Information Technology, 37(4), 311-319. https://doi.org/10.1080/0144929X.2018.1436590 